\title{
Letter to the editor on "the effect of new preoperative preparation method compared to conventional method in complex acetabular fractures: minimum 2-year follow-up"
}

\author{
Tomonori Shigemura $^{1} \cdot$ Yuki Shiratani $^{1} \cdot$ Hiroyuki Hamano ${ }^{1}$
}

Received: 29 May 2020 / Accepted: 15 July 2020 / Published online: 24 July 2020

(c) Springer-Verlag GmbH Germany, part of Springer Nature 2020

We took great interest in reading the article titled "The effect of new preoperative preparation method compared to conventional method in complex acetabular fractures: minimum 2-year follow-up" by Wang et al. [1]. They performed an interesting retrospective study assessing the efficacy and safety of the new method including 3D printing-based preoperative planning, surgical workshop, and contouring of the plate in the surgical treatment of complex acetabular fractures by comparing with conventional method. Although we read the article with pleasure, it must be stated that the research has raised a thought-provoking issue. Through the present Letter to the Editor, we wish to have this opportunity to communicate with the authors.

The authors concluded that the new preoperative preparation method using 3D printed model is an effective and safe method than conventional method in surgical treatment of the complex acetabular fractures, and 3D printed models may help in the better understanding of fracture patterns and surgical planning for younger surgeons. We agree with the latter part of the conclusion, but not the first half.

Several studies showed that anatomical reduction and stable internal fixation for acetabular fracture should be performed to achieve long-term good results [2-4]. However, the authors showed that there was no significant difference in radiographic grades between the groups. Therefore, we think that this study has insufficient evidence that this method is an effective.

We respectfully appreciate that Wang et al. provided us with this important retrospective study. Although there were limits, it is still an excellent research which made great contribution to the literature. However, addressing this issue should be carried out to make the research more clear and logical.

Funding There is no funding source.

\section{Compliance with ethical standards}

Conflict of Interest The authors declare that they have no conflict of interest.

\section{References}

1. Wang P, Kandemir U, Zhang B et al (2020) The effect of new preoperative preparation method compared to conventional method in complex acetabular fractures: minimum 2-year follow-up. Arch Orthop Trauma Surg. https://doi.org/10.1007/s00402-020-03472 $-\mathrm{W}$

2. Ruggieri F, Zinghi GF, Specchia L et al (1987) The treatment of fractures of the acetabulum involving both anterior and posterior columns. Ital J Orthop Traumatol. 13:27-36

3. Moed BR, WillsonCarr SE, Watson JT (2002) Results of operative treatment of fractures of the posterior wall of the acetabulum. $\mathrm{J}$ Bone Joint Surg Am. 84:752-758. https://doi.org/10.2106/00004 623-200205000-00008

4. Gänsslen A, Hildebrand F, Kretek C (2013) Transverse + posterior wall fractures of the acetabulum: epidemiology, operative management and long-term results. Acta Chir Orthop Traumatol Cech. 80:27-33

Publisher's Note Springer Nature remains neutral with regard to jurisdictional claims in published maps and institutional affiliations.

Tomonori Shigemura

tshigepon@yahoo.co.jp

1 Department of Orthopaedic Surgery, Teikyo University

Chiba Medical Center, 3426-3 Anesaki, Ichihara,

Chiba 299-0111, Japan 